\title{
Design and Analysis of Warning System for Aircraft Wingtip Proximity to Hangar Column using Ultrasonic Sensor
}

\author{
1,2 Sutiawan \\ ${ }^{1}$ GMF AeroAsia \\ Tangerang, Indonesia \\ ${ }^{2}$ Master of Mechanical Engineering \\ Swiss German University \\ Tangerang, Indonesia \\ sutiawan@gmf-aeroasia.co.id \\ Henry Nasution \\ Master of Mechanical Engineering \\ Swiss German University \\ Tangerang City, Indonesia \\ henry.nasution@sgu.ac.id
}

\author{
*Dena Hendriana \\ Master of Mechanical Engineering \\ Swiss German University \\ Tangerang, Indonesia \\ dena.hendriana@sgu.ac.id
}

\author{
Hanny J. Berchmans \\ Master of Mechanical Engineering \\ Swiss German University \\ Tangerang, Indonesia \\ hannyjberchmans2020@gmail.com
}

\begin{abstract}
Aircraft maintenance is using very large hangar as a place to work on the aircrafts and the hangar can fit several aircrafts at the same time. The aircrafts are moved using tow cars in and out of the hangar. The hangar is so big that it requires columns for its structure and these columns present risk to the aircrafts for having wingtip collitions during towing in and out of the hangar. In this study, warning system for aircraft wingtip proximity to the hangar columns is designed. This warning system is using ultrasonic sensors attached to the columns and controlled by Arduino micro processor and wirelessly connected as Internet of Things system to warn the driver of the tow car. The ultrasonic sensors are placed in the columns based on dimension and elevation of 2 different most common aircraft wingtips to get effective column warning system. The speed of tow car affects the driver time to response the warning and based on calculations and experiments, the tow car driver should have enough time to respond the warning system.
\end{abstract}

Keywords-column warning system, ultrasonic sensor, proximity warning, internet of things, wingtip collision.

\section{INTRODUCTION}

Aircraft movement activities in the hangar area occurs when the aircraft is entering or exiting the hangar. The aircraft movement is done using tow cars and when this process occurs, the area of the aircraft body must be free from surrounding obstacles to prevent any collisions. A minimum of five personnel are involved in the towing process and their duties are in the cockpit, communication and for monitoring the wing and tail sides to be free from obstacles. When necessary, personnel can signal the tow car driver to reduce speed and brake to avoid any obstacles.
In the Garuda Maintenance Facility (GMF), hangar 4 has a column on the side and this column becomes one of the obstacles during the towing process which requires personnel supervision. The hangar column is designed to have a safe distance when towing, but the actual movement of the aircraft requires large area can creates a hazard collision. The hangar building system should maximize usable flightline frontage while it decreases obstruction of aircraft by providing column-free building [1]. Wingman working procedures for each side ensure that the wingtips are free from obstacles and safe for movements [2]. However, in the process, there are several factors that can cause incident collisions to continue, namely human factors, including lack of awareness, lack of communication, lack of resources and distraction [3]. Personnel who do not pay attention to the safe distance from the obstacle, inability to convey communication during unsafe conditions and not quick responses, lack of personnel, and noisy hangar environments, are problems that can occur related to human factors.

The problem with hangar columns lies in monitoring the safe distance from the aircraft wingtips. It is hoped that this can be solved with the help of ultrasonic to find out the distance. Ultrasonic sensors were used also to measure water level in a container [4]. As has been done previously with the collision prevention method between object and wingtip using a low cost radar unit and adding a video camera attached to the wingtip [5], or using a threedimensional visual indication that is processed from the camera attached to the winglet to monitor the field of view of aircraft path [6] or the method used in the method by attaching proximity sensors, motion sensors, batteries, and switching control to the end of aicraft [7]. So that in this study, we can find out whether the warning system built

*Corresponding Author|Dena Hendriana| Email: dena.hendriana@sgu.ac.id

Tangerang - Indonesia, 28 September 2020 
with ultrasonic input will be able to prevent collisions between the wingtip and hangar column.

\section{METHODS}

Collision prevention method in this research is by designing a warning system that is attached to the column hangar. The warning system gets input from the ultrasonic sensor to determine the distance between the wingtip and column. To monitor the actual distance whether there is an obstacle, the Internet of Things (IoT) system is used which can be accessed and displayed in application.

\section{A. Material for the warning system}

Ultrasonic is acoustical energy above audible frequencies and uses acoustic principles in each of its applications [8]. This sensor will be installed in the hangar column as input to the warning system. The sensor used is the Maxsonar EZ4 MB1040 which has sufficient specifications to measure a distance of up to $645 \mathrm{~cm}$. Arduino Mega 2560 is used as a micro controller to process sensors and is also connected to the NodeMCU board as an IoT module to connect to the cloud server. Google Firebase Realtime is used as the server to receive data from NodeMCU. The outputs of this warning system are two things, namely visual warning (Caution with Yellow Light) and a combination of audio and visual (Warning with Red light and buzzer).

\section{B. Ultrasonic Sensor Capability}

Ultrasonic Maxsonar is a type of distance detection sensor from Maxbotix. This study used ultrasonic type MB1040 which is one of the variants of LV Maxsonar EZ Series. Selection of ultrasonic sensors is based on the object to be detected, namely aircraft component in the form of wingtip. Testing was done by placing an object at a certain angle with a certain distance. The time of Flight of the ultrasonic signal is measured by Arduino micro controller and the distance of the object is calculated with velocity of sound in air using the following formula

$$
D_{o}=T_{o f} V_{s}
$$

Where

$$
\begin{array}{ll}
D_{o} & =\text { Distance of the object detected }(\mathrm{m}) \\
T_{o f} & =\text { Time of flight }(\text { second }) \\
V_{S} & =\text { Velocity of sound in air }(\mathrm{m} / \mathrm{s})
\end{array}
$$

Experiments using MB1040 ultrasonic sensor with the object detected in the form of a leading edge wingtip simulation as block part, with length $1 \mathrm{~m}$, width $4 \mathrm{~cm}$, and height $11 \mathrm{~cm}$. The purpose of the experiment is to determine the capability of the sensor and the results show that the sensor is able to read objects in front of it with range of reading from $14.12 \mathrm{~cm}$ to $639.78 \mathrm{~cm}$. The beam angles for the horizontal and vertical distance are shown in Fig. 1 and Fig. 2. The data shows that for horizontal case, the sensor can read up to $55^{\circ}$ effectively and the distance of about $444.5 \mathrm{~cm}$ and for vertical case, it can measure the object up to $35^{\circ}$.

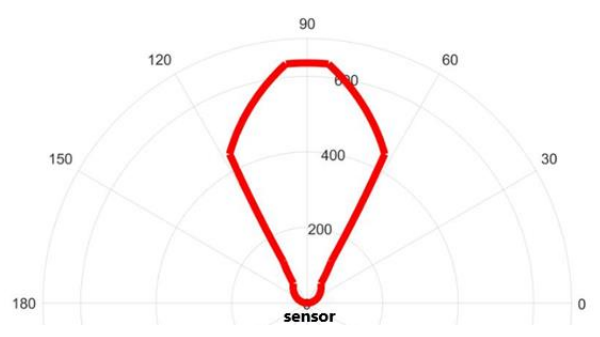

Fig. 1. Sensor reading in horizontal beam angle.

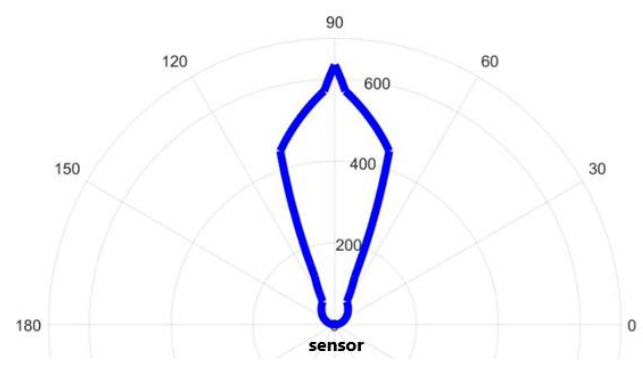

Fig. 2. Sensor reading in vertical beam angle.

\section{Internet of Things communication}

The Arduino can communicate with NodeMCU using Software Serial with digital pins to replicate functionality. The Arduino Software Serial uses 9600 baud rate to start serial port and NodeMCU works at 115200 baud rate. From the NodeMCU board, it continues sending data from NodeMCU to Database in Firebase Realtime. Firebase is a service that is used to store data that we use on applications or IoT systems from Google. When using Firebase, we will be dealing with several features namely, Authentication, Hosting, Cloud Storage, and Realtime Database. Utilization for the IoT usually uses the Realtime Database feature as a cloud server that is able to receive data from sensors in Realtime. The data used in this research is taken from NodeMCU which is connected to the internet. This Windows Form App was created to be an interface for monitoring the distance between wingtips and hangar columns in real time. The distance display is taken from the cloud database data which is used to store data from NodeMCU. The cloud must be able to be accessed by the App in realtime by connecting to the internet. The process of developing this App uses Visual Studio 2019 Software. The data displayed is the value of the distance between the wingtip and the column.

\section{RESULT AND DISCUSSION}

The design for experimental is using materials and multiple sensors to build warning system for prototyping. Several analyzes were carried out after conducting the assembly and before testing. We must know the area of the wingtip that is needed to be monitored so that the placement of the sensor in the hangar column is more effective. The speed of towing car is in considerations which have an important role in determining the warning system distance and analysis of the placement of the ultrasonic on the column. 


\section{A. Wingtip Effective Area Monitored}

In this study, the type of aircraft included in the wingtip analysis are Boeing 737-800 [9] and CRJ1000 aircraft [10]. Both of these aircraft have wingtip mounted winglets on their ends. The winglets have different dimensions for each type of aircrafts. The dimensions for the type analyzed are as follows in Table 1 and Fig. 3:

TABLE 1.

WINGTIP (WINGLET) DIMENSION

\begin{tabular}{lcc}
\hline Winglet dimension & Boeing & CRJ1000 \\
\hline Lower tip (from ground) & $2.49 \mathrm{~m}$ & $1.93 \mathrm{~m}$ \\
\hline Upper tip (from ground) & $6.43 \mathrm{~m}$ & $3.25 \mathrm{~m}$ \\
\hline Length (vertically) & $3.94 \mathrm{~m}$ & $1.32 \mathrm{~m}$ \\
\hline
\end{tabular}

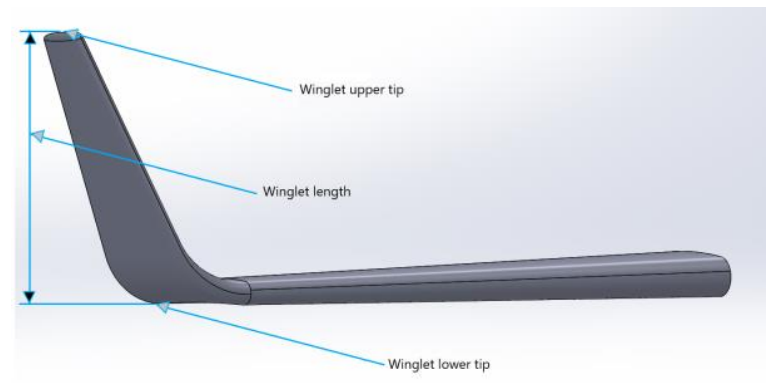

Fig. 3. Winglet tip elevation and length

\section{B. Tow Car Speed Consideration}

In addition to the analysis of the monitored area, this section discusses the consideration of tow car speed when towing and pushing-back. Referring to the internal procedure for towing and pushing-back in Garuda Indonesia Company maintenance manual, the towing speed should be kept in safe speed of $5 \mathrm{~km} / \mathrm{h}(1.35 \mathrm{~m} / \mathrm{s})$, and maximum towing speed of $15 \mathrm{~km} / \mathrm{h}(4.05 \mathrm{~m} / \mathrm{s})$. Also, there is another regulation in towing speed not to be more than commonly human walking speed. Human walking speed in healthy condition is $1.20 \mathrm{~m} / \mathrm{s} 1.40 \mathrm{~m} / \mathrm{s}$ [11].

We use the maximum speed of $1.40 \mathrm{~m} / \mathrm{s}$ as reference for consideration to know the distance covered for warning system. This is used for distance range calculation in the warning system design. It is compared to mean response time in the lowest response to audio and visual warnings. Fig. 4 shows mean response time in elderly to visual is $614 \mathrm{~ms}$ [12], and for multi warning using audio and visual is $527 \mathrm{~ms}$, as the lowest time in relation with developed warning system in this study.

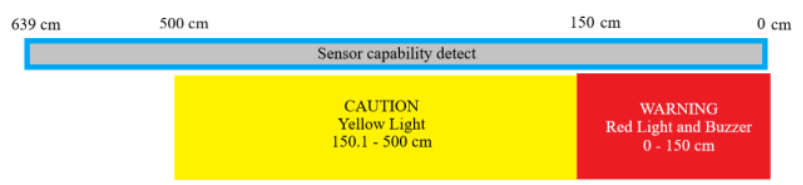

Fig. 4. Distance range for caution and warning system

\section{Sensor Positioning Analysis}

The hangar column to be monitored is a rectangular box of $3.5 \mathrm{~m} \mathrm{x} 3.5 \mathrm{~m}$ and the height of up to $16 \mathrm{~m}$. Based on the sensor range from $14.7 \mathrm{~cm}$ to $639 \mathrm{~cm}$, the sensor position is designed in the position as shown in Fig. 5. There are 5 sensors for each side of column which means 20 sensor for all sides in upper monitoring area. For upper and lower monitoring areas, the total of 40 sensors are needed. Positions of the sensors for every side of column is that sensor 1 at edge column with $17.5^{\circ}$ angle to the normal of column surface, Sensor 2 is $67.5 \mathrm{~cm}$ perpenticular to the column surface, sensor 3 is $175 \mathrm{~cm}$, sensor 4 is $282.5 \mathrm{~cm}$ from edge, and sensor 5 is at another edge with $17.5^{\circ}$ angle.

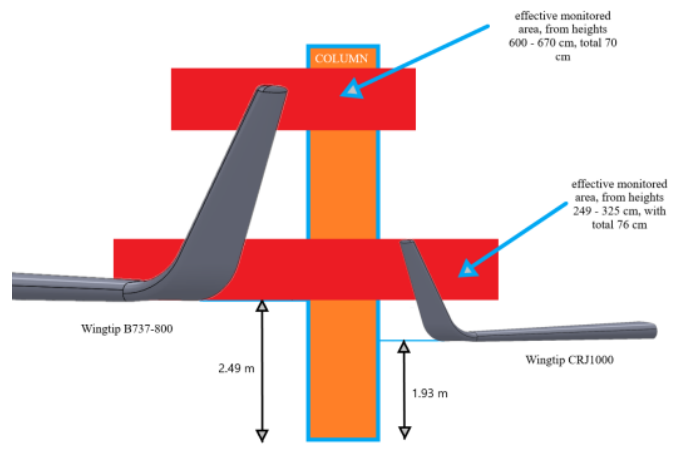

Fig. 5. Effective upper and lower monitoring areas

\section{Experimental Results}

Experiments were done on a column model using 4 ultasonic sensors to cover monitoring area to test the design of warning system when detecting approaching objects around it, see Fig. 6. The component used in this experiment as an object is aluminum foil coated component that forms the winglet tip contour. Its dimension is $1 \mathrm{~m}$ length, $4 \mathrm{~cm}$ width and $11 \mathrm{~cm}$ height. Response time when the sensors sensing the object will be read directly in the application. The value is recorded at each experiment to determine the response time and the calculated distance. In addition response time and calculated distance for caution, the outputs of this warning system model is also buzzer and warning light. The actual object distance is measured in this model.

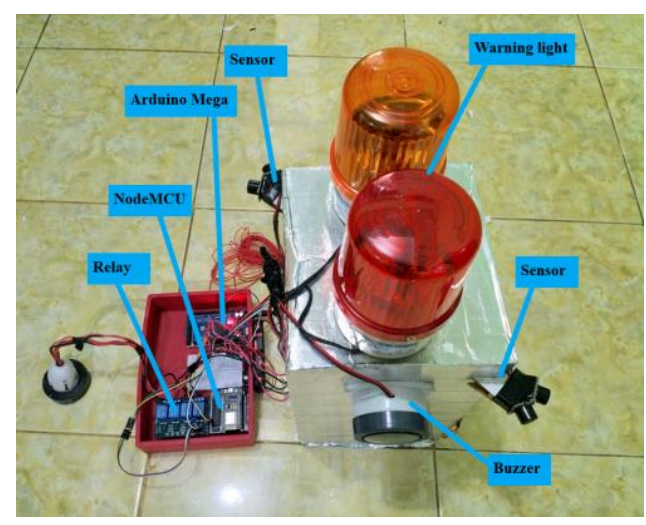

Fig. 6. Design prototyping system 
Fig. 7 shows the driver elapsed time to respond the caution and warning signals for different towing speed. The speeds of $1.4 \mathrm{~m} / \mathrm{s}, 1.2 \mathrm{~m} / \mathrm{s}, 1.0 \mathrm{~m} / \mathrm{s}$, and $0.7 \mathrm{~m} / \mathrm{s}$ are used in the analysis.

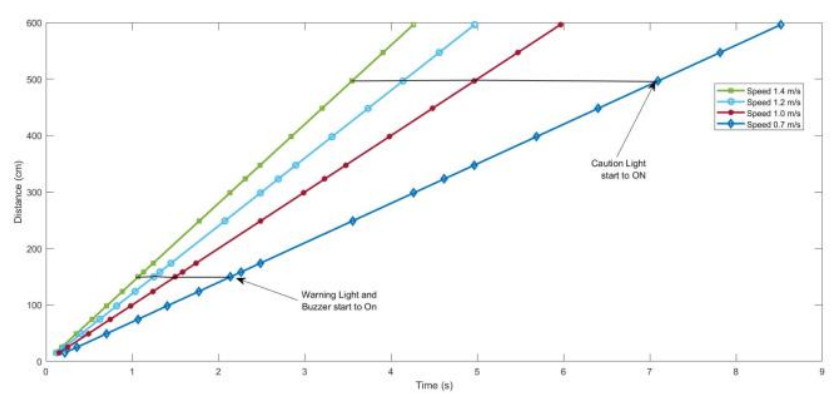

Fig. 7. Driver response time for different towing speeds.

Fig. 8 shows the response time of the driver to the caution and warning lights and buzzer as a function of towing speed. For towing speed of $1.4 \mathrm{~m} / \mathrm{s}$, the driver has around 3.5 second response time for caution light and around 1 second for warning light. This should give enough time for the driver to make safety actions. The slower the towing speed, the larger is the response time that the driver has.

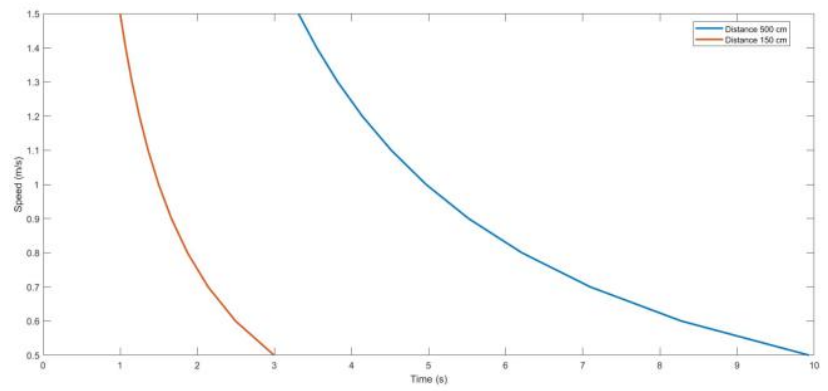

Fig. 8. Driver response time as a function of towing speed.

By considering the response time to both audio and visual warnings, which is 614 millisecond for visuals, and 527 millisecond for multi warnings, we can determine towing car speeds that are quite safe in operation when approaching or passing through the column area. With a speed of $0.7 \mathrm{~m} / \mathrm{s}$ tow car, we can get a caution response time of $7.09 \mathrm{~s}$, and a warning response time of $2.14 \mathrm{~s}$. This time is safe enough to respond to the warnings, so the 0.7 $\mathrm{m} / \mathrm{s}$ speed can be recommended to the tow car operator.

\section{CONCLUSION}

The ultrasonic warning system is studied to avoid collition of aircraft wingtip to hangar column during towing and pushing-back by tow car in maintenance process. The warning system is based on Arduino Mega 2560 Micro Controller with ultrasonic sensor of Maxbotix MB1040 to detect approaching objects and NodeMCU for communicating device as IoT component. Sensing range of ultrasonic sensor has been studied resulting optimal position of ultrasonic sensors in the column. Two common aircrafts, Boeing 737-800 and CRJ1000, are used to define the elevation position of sensors in the column. Outputs of the warning system is visual and audio, such as warning light and buzzer. With towing car speed of $1.4 \mathrm{~m} / \mathrm{s}$, the driver has around 3.5 second to respond to the caution light and buzzer, and around 1 second to respond to the warning light and buzzer. This should be enough time for the driver to make safety actions. It is recommended to the driver to run slower towing car speed when approaching the column area for safety reason.

\section{ACKNOWLEDGMENT}

I would like to express my deep gratitude and profound thanks for research collaborations to Mr. Dena Hendriana, B.Sc., S.M., Sc.D., and Dr. Ir. Hanny J. Berchmans, M.Sc., as lecturers in Swiss German University.

\section{REFERENCES}

[1] D. of defense USA, Design : Aircraft Maintenance Hangars :Type I and Type II, Encycl. Soc. Meas., no. October, pp. 883-888, 2004.

[2] GMF Work Instruction, Work Instructions Wi-Pf-002 Aircraft Push Back, Towing and Parking. 2020.

[3] I. Floriana, The Dirty Dozen, vol. 1, 2016.

[4] Mulyono and H. J. Berchmans, "Design and simulation of water level monitoring and control system in mini hydro power plant, $1^{\text {st }}$ Proceedings of The Conference on Management and Engineering in Industry (CMEI 2019)," vol. 1, pp. 13-16, Tangerang, Indonesia, August 2019

[5] B. Tognazzini, Aircraft Ground Collision Avoidance System and Method, 2000.

[6] R. Odell, F. Manochio, J. Meade, and M. Boost, Methodes and Systems for Collision Avoidance using Visual Indication of Wingtip Path, 2016.

[7] N. J. Duerksen and D. Papadopoulos, Proximity Detection System, 2017.

[8] D. Ensminger and F. B. Stulen, Ultrasonics: Data, Equations and their Practical uses. 2008.

[9] Boeing, B737 Dimensions and Area, 2019.

[10] Bombardier, Dimension and Area. 2019.

[11] A. R. Wu, C. S. Simpson, E. H. F. V. Asseldonk, H. V. D. Kooij, and A. J. Ijspeert, "Mechanics of very slow human walking," Sci. Rep., 9 (1), pp. 1-10, 2019.

[12] P. J. Laurienti, J. H. Burdette, J. A. Maldjian, and M. T. Wallace, "Enhanced multisensory integration in older adults," Neurobiol. Aging, 27 (8), pp. 1155-1163, 2006. 